\title{
The oct-1 homeo domain contacts only part of the octamer sequence and full oct-1 DNA-binding activity requires the POU-specific domain
}

\author{
C. Peter Verrijzer, Arnoud J. Kal, and Peter C. van der Vliet \\ Laboratory for Physiological Chemistry, University of Utrecht, NL-3521 GG Utrecht, The Netherlands
}

\begin{abstract}
The ubiquitous octamer-binding protein oct-1 contains a POU domain required for DNA binding, which can be subdivided into a POU-specific domain and a POU homeo domain. We have overproduced the POU domain and the POU homeo domain in a vaccinia expression system, purified both polypeptides to near homogeneity, and compared their DNA-binding properties. In contrast to the POU domain, the homeo domain protects only part of the octamer sequence in the Ad2 origin against breakdown by DNase I or hydroxyl radicals. Analysis of purine contacts by DMS and DEPC interference assays shows that the Ad2 octamer can be divided into two regions: one that is recognized both by the POU domain and the homeo domain in an identical fashion, and one that is only recognized by the POU domain. This suggests that the POU-specific domain is responsible for the additional contacts located at one side of the octamer. In agreement with this, mutating the first 3 nucleotides (ATG) of the octamer affected binding by the POU domain but not by the homeo domain. The apparent binding affinities to different octamer sites were compared. The homeo domain binds 600 -fold less efficiently to the canonical octamer sequence (ATGCAAAT) than the POU domain. The difference is only sevenfold for the Ad2 octamer, whereas both $K_{d}$ values are almost identical for the HSV ICP4 TAATGARAT motif. Both the POU and homeo domains recognize target sequences for mammalian homeo box proteins. We conclude that the octamer can act as a bipartite recognition sequence for oct-1 and that the POU-specific domain contributes to the binding affinity, as well as to the specificity, by providing additional contacts.
\end{abstract}

[Key Words: POU domain; homeo box; transcription factor; octamer sequence; contact points]

Received June 14, 1990; revised version accepted August 20, 1990.

Crucial cellular processes like DNA replication and transcription are regulated by sequence-specific DNAbinding proteins. One of these, the ubiquitous transcription factor oct-1, also referred to as NFIII, OTF-I, OBP100, or NF-AI, is a $90-$ to $95-\mathrm{kD}$ nuclear protein that binds to the octamer element (Pruijn et al. 1986; Singh et al. 1986; Fletcher et al. 1987; Sturm et al. 1987; O'Neill and Kelly 1988). The octamer is an essential component of promoters and enhancers of several cellular genes like histone $\mathrm{H} 2 \mathrm{~B}, \mathrm{U1}$ and $\mathrm{U} 2$ small nuclear RNAs (snRNAs), and immunoglobulin light and heavy chains. It is also present in the adenovirus origin of DNA replication, where it mediates a four- to sixfold enhancement of initiation by oct-1 (Pruijn et al. 1986; Wides et al. 1987). The contacts between oct- 1 and its binding sites were examined in some detail (Baumruker et al. 1988; Pruijn et al. 1988). Both minor and major groove base contacts were detected, as well as many backbone contacts at both sides of the DNA helix. Comparison of several degenerated binding sites indicated that specific binding may reflect the sum of many independent interactions between protein and DNA in agreement with promiscuous sequence recognition of oct-1 (Baumruker et al. 1988). Analysis of the oct-1 cDNA sequence (Sturm et al. 1988) has indicated the presence of a conserved region involved in DNA binding, the POU domain. This 150- to 160-amino-acid-long region was first recognized in the transcription factors Pit-1 (Bodner et al. 1988; Ingraham et al. 1988), oct-1 (Sturm et al. 1988) and oct-2 (Clerc et al. 1988; Ko et al. 1988; Müller-Immerglück et al. 1988; Scheidereit et al. 1988), and the nematode Caenorhabditis elegans unc-86 gene product (Finney et al. 1988; for review, see Herr et al. 1988). A search for other POU domain-containing proteins led to the discovery of several other POU proteins forming a family of transcription factors all recognizing the octamer sequence. So far, five different classes can be distinguished, based on sequence homology (He et al. 1989; Schöler et al. 1990). They are present in murine tissue at different stages of development (Lenardo et al. 1989; Schöler et al. 1989a,b; Okamoto et al. 1990), in adult human and rat brain (He et al. 1989), chicken (Petryniak et al. 1990), Xenopus laevis (Smith and Old 1990), C. elegans (Bürglin et al. 1989), and Drosophila (Johnson 
and Hirsh 1990), where they may function as neurospecific transcription factors.

Apart from DNA binding, the oct-1 POU domain is also sufficient for adenovirus DNA replication (Verrijzer et al. 1990). Furthermore, the homeo domain directs the interaction with the herpes simplex virus (HSV) transactivator VP-16 or Vmw65 (Stern et al. 1989; for review, see Goding and O'Hare 1989|. The POU domain can be subdivided into a POU-specific domain (amino acids 279-354) and a homeo domain (amino acids 379-439) connected by a variable nonconserved linker region. The oct-1 homeo domain is homologous to the homeo domains found in many homeotic genes (for review, see Scott et al. 1989). Although an intact homeo domain is required for DNA binding, the oct-1 homeo domain does not represent the full DNA-binding activity of the oct-1 protein (Sturm and Herr 1988; Verrijzer et al. 1990). This is in contrast to the classical homeo box genes (Hall and Johnson 1987; Mihara and Kaiser 1988; Müller et al. 1988). Based on the failure to detect DNA binding of the oct-1 homeo domain in the absence of an intact POUspecific domain, a bipartite DNA-binding structure has been proposed (Sturm and Herr 1988) in which, in addition to the homeo domain, the POU-specific domain is required for binding, for example, by providing additional contacts. An alternative explanation for these experiments, suggested by García-Blanco et al. (1989), is that binding to the octamer sequence would be specified solely by the homeo domain. In this view, the POU-specific domain could enhance the binding by stabilizing existing protein-DNA interactions of the homeo domain.

Recently, we showed that the isolated oct-1 homeo domain is able to recognize the octamer but with a reduced affinity compared to the intact POU domain /Verrijzer et al. 1990). Here, we investigate the reason for this reduction by an analysis of the contacts between DNA and the homeo domain. We present evidence that the POU-specific domain contributes to the binding affinity of the POU domain by making additional DNA contacts, thereby influencing the specificity of binding. We propose that although the homeo domain is the DNAbinding core, the POU domain is a true bipartite DNAbinding structure recognizing two distinct regions of the octamer sequence.

\section{Results}

DNase I footprint borders of the POU domain and the homeo domain differ

We overproduced the oct-1 POU domain and the homeo domain employing recombinant vaccinia viruses constructed as described before (Verrijzer et al. 1990). The two polypeptides were isolated from infected HeLa cells and purified by standard chromatographical procedures (see Materials and methods). From 6 liters of HeLa cells, $400-500 \mu \mathrm{g}$ highly purified protein was obtained, as determined by SDS-gel electrophoresis (Fig. 1). We compared the DNase I footprint borders of the POU domain
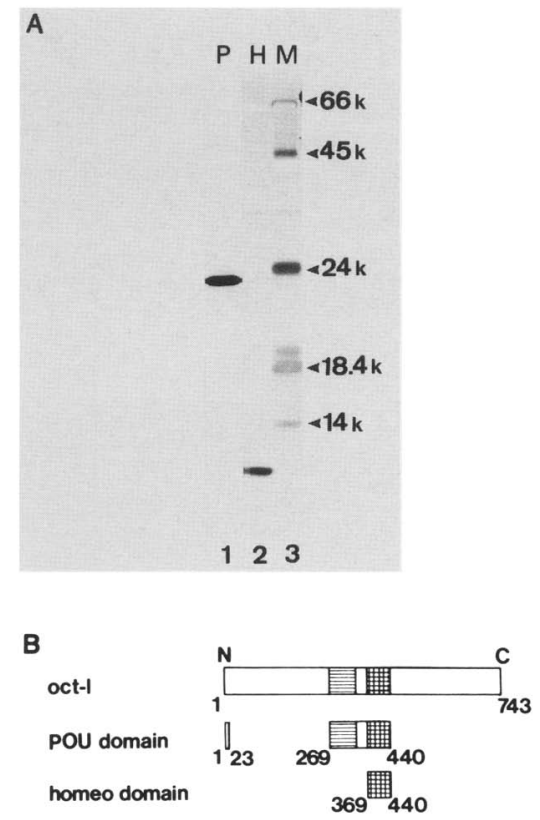

Figure 1. (A) Silver-stained polyacrylamide gel of purified vaccinia-expressed POU domain and homeo domain. (Lane 1) 1.4 $\mu \mathrm{g}$ POU domain (P). (Lane 2) $0.8 \mu \mathrm{g}$ homeo domain (H). (Lane 3) Marker lane with bovine milk $\alpha$-lactalbumin $(14 \mathrm{kD})$, bovine milk $\beta$-lactoglobulin (18.4 kD), bovine pancreas trypsinogen (24 $\mathrm{kD}$ ), ovalbumin $(45 \mathrm{kD})$, and bovine serum albumin $(66 \mathrm{kD}) .(B)$ Structure of the oct- 1 protein and the domains that were expressed. The numbering of the oct-1 amino acids is derived from Sturm et al. (1988).

with those of the homeo domain, using the octamer sequence present in the Ad2 origin of DNA replication. Figure 2 shows that the regions protected by the homeo domain footprint are shorter on both strands. On the top strand, phosphate bonds 36 (the bond on the 3' side of nucleotide 36) to 56 are protected by the POU domain, and phosphate bonds $40-56$ are protected by the homeo domain. On the bottom strand, the footprint extended from phosphate bonds $54\left(3^{\prime}\right.$ side of nucleotide 54$)$ to 34 for the POU domain and from 54 to 39 for the homeo domain, making the homeo domain footprint 4 nucleotides shorter on the top strand and 5 nucleotides shorter on the bottom strand. Remarkably, the difference was located at one side only, defined here as the left side of the recognition sequence proximal to the molecular end, whereas the borders at the right side coincided completely. It should be emphasized that the footprint borders of the POU domain are identical to those determined previously for the intact protein using the same probe (Pruijn et al. 1986).

\section{Contact points within the Ad2 origin binding site}

To compare contact points of the POU domain and the homeo domain with their recognition sequence, we employed hydroxyl radical footprinting and chemical modification interference assays. 


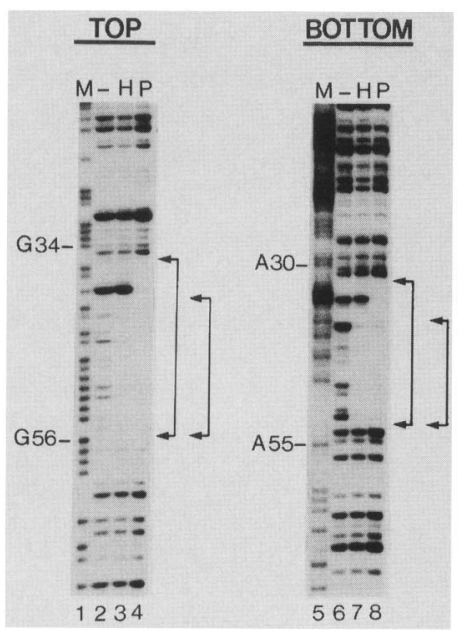

Figure 2. DNase I footprint analysis of the POU and homeo domain interaction with both strands of the Ad2 octamer motif. The marker lane (M) shows the location of the purines numbered according to their position in the $\mathrm{Ad} 2$ origins. (Lanes 2,6 ) No protein; (lanes 3,7) $60 \mathrm{ng}$ homeo domain; (lanes 4,8) 40 ng POU domain. The protected regions are indicated.

\section{Hydroxyl radical footprinting}

Hydroxyl radicals, generated by iron(II)-promoted reduction of hydrogen peroxide, attack the deoxyribose residues in the DNA backbone. Sugars in close contact with protein are completely or partially protected against cutting. This enables precise mapping of the backbone contacts made by a DNA-binding protein (Tullius and Dombroski 1986). Figure 3 shows the hydroxyl radical footprints of the POU domain and the homeo domain on the Ad2 origin. Densitometric scanning of the results of several independent experiments reveals that the POU domain partially protects two regions on both strands: a small, weakly protected region around position 38 on the top strand and position 36 on the bottom strand, and a larger, strongly protected region, mainly from position 43 to 48 on the top strand and from 42 to 45 on the bottom strand. Between these two protected regions, weak hypersensitivity is observed at position 41 on the top strand and positions 38 and 39 on the bottom strand. The homeo domain only protects the larger region. In that part of the octamer, protection is almost identical to that by the POU domain. In contrast to the POU domain, the homeo domain does not induce any hypersensitivity. At the top of the gel an additional footprint by the homeo domain can be seen. The protected sequence ${ }^{9} \mathrm{ATAATA}^{14}$ is very similar to the right part of Ad2 octamer (ATAATG).

\section{$D M S$ and DEPC interference}

Interference assays are based on the observation that modification of bases, which are contacted by a bound protein, will reduce binding. Bound and unbound DNA can be separated by gel retardation and analyzed on sequence gels after specific strand cleavage at the modified nucleotide. Under-representation of a band in the bound fraction of DNA is interpreted as a contact.

Assuming B-DNA conformation, dimethylsulfate (DMS) methylates guanine residues at the N7 position in the major groove and adenine residues at the $\mathrm{N} 3$ position in the minor groove. Alkylation also adds a positive charge and thus changes the resonance state of the purine ring, which could obscure the assignment of minor groove contacts. DMS is especially sensitive for identification of guanine contacts, whereas adenine contacts are often more difficult to detect. Sturm et al. (1987) introduced diethyl pyrocarbonate (DEPC) as a powerful tool for the identification of adenine contacts. DEPC modifies the N7 position of free purines with a preference for adenine.

Figure 4A shows the results of a DMS interference assay. Methylation of G42 at the top strand clearly aborted binding of the POU domain but not the homeo domain. Adenine residues were hardly detectable for the top strand. On the bottom strand, methylation of adenines 39, 41, 44, and 47 affected POU domain binding, whereas only methylation of adenines 44 and 47 impaired binding for the homeo domain.

DEPC interference (Fig. 4B) identified POU domain contacts at G42 and adenines $38,40,43,45$, and 46 on the top strand and adenines $39,41,44$, and 47 on the bottom strand, which agrees completely with the contacts of intact oct-1 (OBP100) with the Ad2 origin, identified by Baumruker et al. (1988). A smaller number of adenine contacts were made by the homeo domain, at

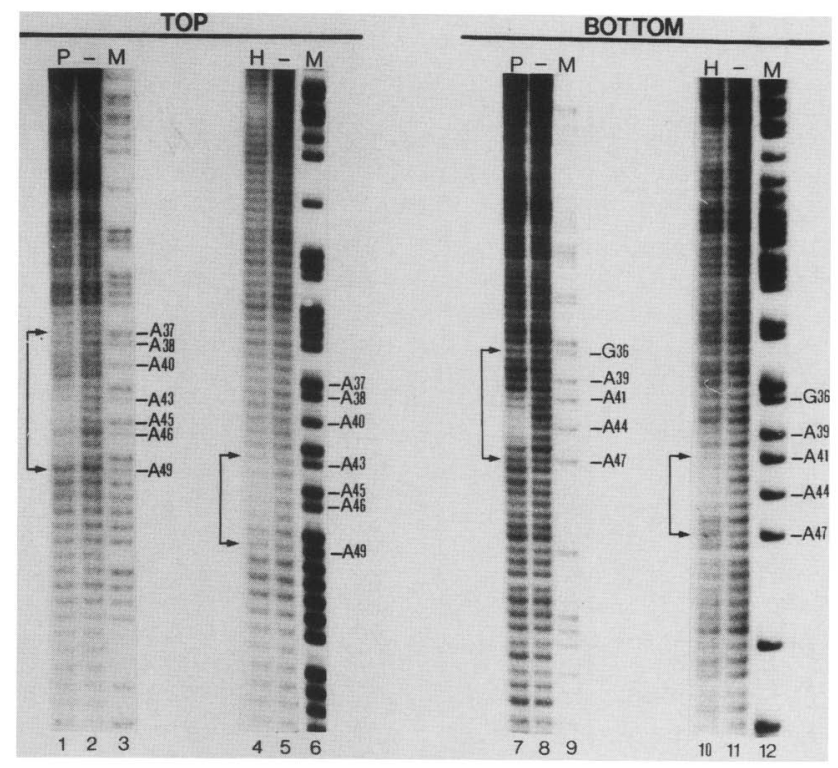

Figure 3. Hydroxyl radical footprints of the POU domain and homeo domain on the Ad2 origin. DNA fragments labeled at top or bottom strand were treated with hydroxyl radicals after incubation with $40 \mathrm{ng}$ POU domain ( $\mathrm{P}$, lanes 1,7), $100 \mathrm{ng}$ homeo domain $(\mathrm{H}$, lanes 4,10$)$, or without protein (lanes $2,5,8,11)$. Products were analyzed on an $8 \%$ polyacrylamide gel in parallel with $A+G$ sequence reaction $(M)$. Numbers indicate positions in the Ad2 origin. The protected regions, as determined by scanning, are indicated. 

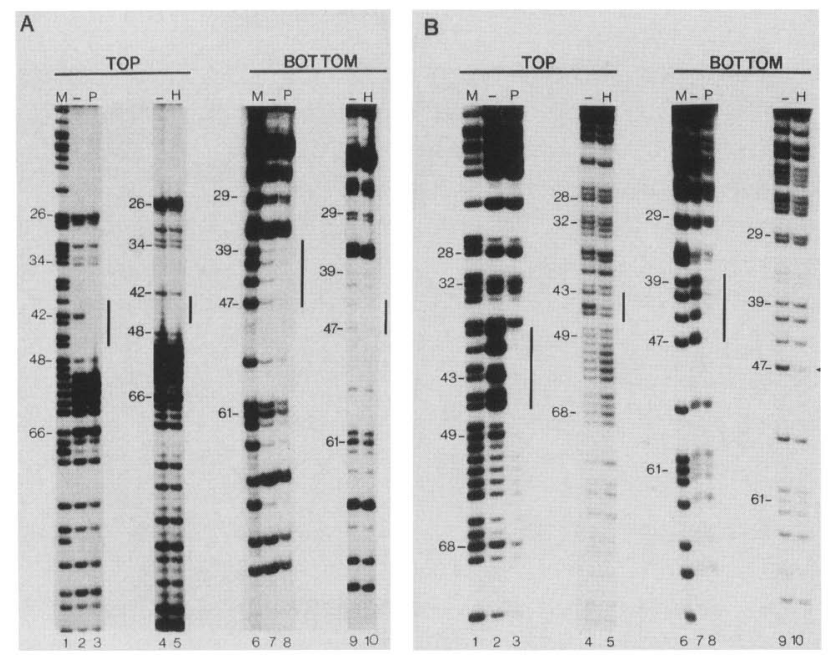

Figure 4. DMS and DEPC modification interference analysis. The Ad2 origin DNA was partially methylated with DMS in $A$ and with DEPC in $B$. Modified end-labeled DNA fragments were incubated with the POU domain or the homeo domain. Bound and free DNAs were separated by gel retardation and recovered in a POU domain-free fraction (lanes 2,7), a POU domain-bound fraction (lanes 3,8 ), a homeo domain-free fraction (lanes 4,9), and a homeo domain-bound fraction (lanes 5,10). After cleavage at modified residues the fractions were analyzed on an $8 \%$ polyacrylamide gel in parallel with an $A+G$ sequence reaction (M). Numbers indicate positions in the Ad origin. The regions of interference are indicated with a bar.

positions 43,45 , and 46 on the top strand and only 47 on the bottom strand. Again, this shows the absence of contacts at the left part of the octamer. Generally, the interference of modifications with homeo domain binding seems to be weaker than with binding of the POU domain. Possibly, when present in the POU domain, the homeo domain is forced deeper into the DNA and is therefore more sensitive to modification of the bases.

The results obtained for A44 are interesting, because DEPC modification (carbethoxylation at N7, major groove) does not interfere with homeo domain binding but DMS modification (methylation at N3, minor groove/ does interfere. This suggests that this nucleotide is contacted in the minor groove only. However, POU binding is hampered both by DMS a d DEPC modification of A44, implying that the PC.J-specific domain is responsible for the major groove contact.

\section{The POU-specific domain is responsible for protein- DNA contacts}

In Figure 5 we have summarized all contacts that were identified. The backbone contacts of the POU domain consist of two regions, enclosing some nucleotides with weak hypersensitivity for hydroxyl radicals. This might reflect the induction of structural changes in this region due to binding of the protein. Base contacts made by the POU domain are observed for every base pair in the core octamer sequence (40-47), as well as at two positions in

front of the octamer. An impression of the spatial distribution of these contacts is given. Both sides of the DNA helix are contacted, and the total contacted region spans $14 \mathrm{bp}$. The homeo domain contacts span $9 \mathrm{bp}$, all located in the right part of the octamer, both in the minor and the major groove.

\section{Oct-1 POU and homeo domains differ in binding specificity}

We studied the specificity of sequence recognition by comparing binding of the POU and homeo domains to several octamer motifs. Figure 6 shows that a canonical octamer (Ad4, AATATGCAAATAAGGC), which is optimal for oct-1 binding (Pruijn et al. 1987), hardly binds the homeo domain. In contrast, the herpes simplex ICP4 TAATGARAT motif (AGGGCGGTAATGAGAT; for review, see Goding and O'Hare 1989|, which deviates at five of eight positions from the canonical octamer, has a strong affinity for the homeo domain and is suboptimal for POU binding (Fig. 6A, lanes 8 and 9).
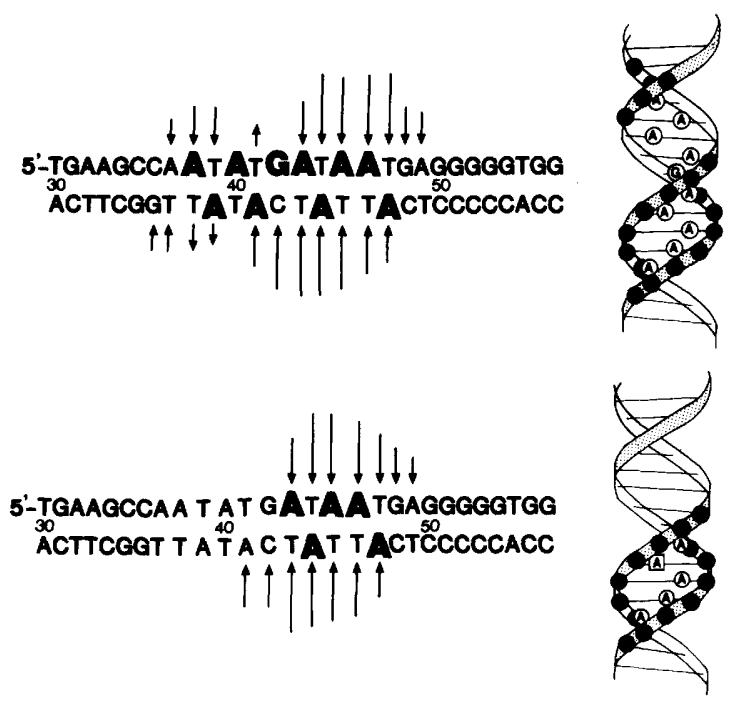

Figure 5. Summary of the contacts that were identified for the POU domain and the homeo domain on the Ad2 origin. Nucleotides whose deoxyribose is protected from attack by hydroxyl radicals are indicated with arrows, with the lengths of the arrows indicating the level of protection. Arrows pointing away from the bases show hypersensitive sites. Values were calculated from the scanning of five independent experiments. The maximum protection level obtained was $95 \%$. Bases whose modification by DMS or DEPC interferes with complex formation are in boldface type. All contacts indicated results from an at least twofold reduction in band intensity in the complexed sample, as determined by densitometric scanning. Contacts are also mapped onto a scheme of B-DNA. The direction from which we view the DNA is arbitrary and is not meant to indicate the side of the helix where the protein is situated. Solid circles along the DNA backbone represent deoxyriboses protected from hydroxyl radical attack. Circled purines represent bases whose modification by DEPC or DMS interferes with binding. A44 is boxed to indicate that only DMS methylation interferes with homeo domain binding, while both DMS and DEPC modification at this position abort POU domain binding. 


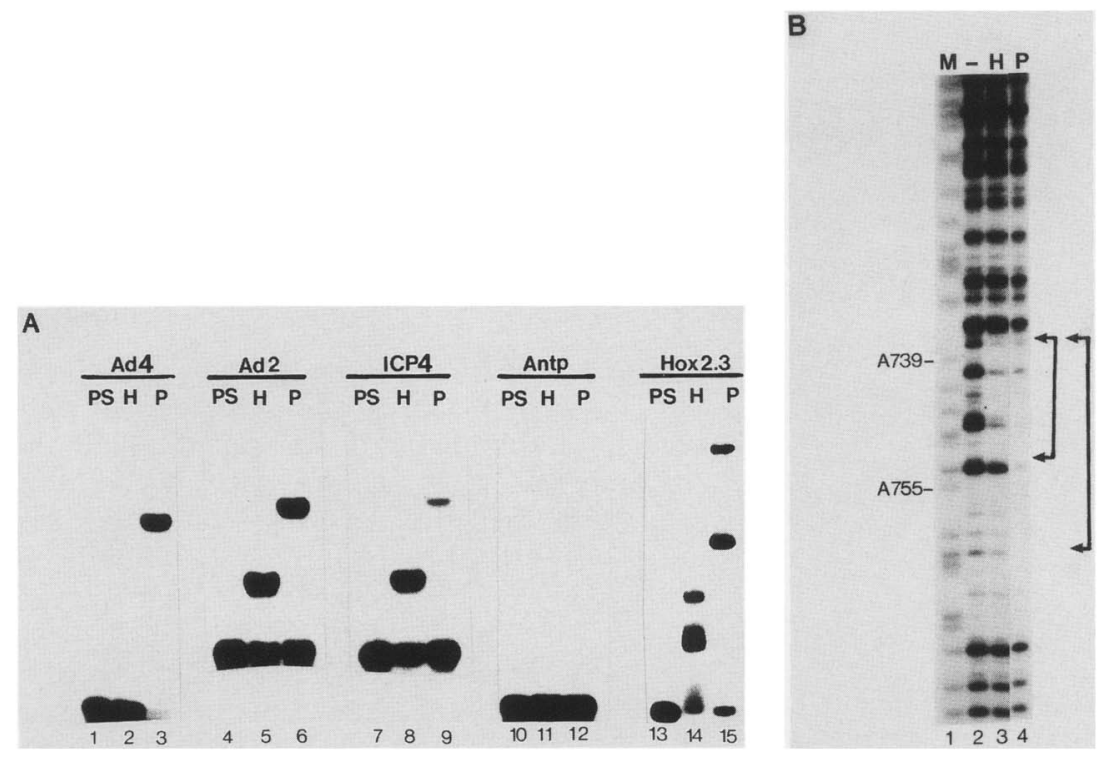

Figure 6. Binding of the POU and homeo domains to degenerate octamer motifs and cellular homeo box protein recognition sequences. (A) Probes containing the octamer motifs from the Ad4 origin (lanes 1-3), the Ad2 origin (lanes 4-6), the HSV ICP4 TAATGARAT motif (lanes 7-9), the Antp BS-2 site (lanes 10-12), or the Hox-2.3 promoter region (lanes 13-15) were incubated with a cytoplasmic extract containing the POU-specific domain (PS), 2 ng purified POU domain (P), and 10 ng purified homeo domain (H) and separated on a $15 \%$ native polyacrylamide gel (lanes 1-12). Samples $13-15$ were assayed in a separate experiment and analyzed on a $12 \%$ polyacrylamide gel. $(B)$ Footprint analysis of the homeo and POU domains on the Hox-2.3 $\beta$ site. The marker lane (M) shows the locations of the purines numbered according to their positions in the Hox-2.3 promoter region. Partial DNase I digestion was in the absence of protein (lane 2) or in the presence of $200 \mathrm{ng}$ homeo domain (lane 3) or POU domain (lane 4). The protected regions are indicated.

The part of the Ad2 octamer contacted by the oct-1 homeo domain (ATAATGA) shows a clear similarity to homeo box protein recognition motifs (Desplan et al. 1988; Hoey and Levine 1988; Scott et al. 1989). The Drosophila Antennapedia (Antp) sites, for example, all contain a conserved TAATG motif (Müller et al. 1988). To test directly whether the oct-1 homeo domain binds to such a sequence, we performed a band-shift assay with the Antp BS2 site (Affolter et al. 1990). Despite its high similarity to the Ad2 octamer (see Fig. 8, below), the Antp BS2 site was not bound by the oct-1 homeo domain nor the POU domain (Fig. 6, lanes 10-12). Apparently, mutations from ATAATGA to CTAATGG abolish binding. In the murine Hox-2.3 promoter region, two different sites, $\alpha$ and $\beta$, are recognized by the Hox-1.3 homeo box protein (Odenwald et al. 1989) and probably also by the Hox-2.3 protein itself (R. de Jong and F. Meijlink, pers. comm.). We tested a radiolabeled fragment containing both Hox-2.3 sites $(\alpha$, CAGTAATGA; $\beta$, TCAATAATGA). The POU and homeo domains bind both sites, as indicated by the formation of two complexes (Fig. 6A, lanes 14 and 15). Comparison of DNase I footprints of the POU and homeo domains on the Hox-2.3 $\beta$ site (Fig. $6 \mathrm{~B}$ ) shows that, like on the Ad2 octamer, the homeo domain footprint is shorter at only one side of the recognition site. The extension of the additional sequence protected by POU is in the same direction as on the Ad2 octamer sequence, suggesting an identical orientation of the POU domain. None of the probes tested gave any binding of the POU-specific domain (Fig. 6, lanes 1, 4, 7, 10, and 13). The presence of the POU-specific domain in recombinant vaccinia-infected HeLa cell extracts was verified by polyacrylamide gel electrophoresis.

The contribution of the POU-specific domain to the binding affinity depends on the recognition sequence

We used the band shift assay for a quantitative comparison of the POU and homeo domain-binding affinities by increasing the protein concentration at a fixed probe concentration of $2 \times 10^{-10} \mathrm{M}$ in the absence of competitor DNA (Fig. 7A). As shown in Figure 7B, the POU domain concentration required for half-saturation of the Ad4 probe was $1.9 \times 10^{-10} \mathrm{M}$, whereas a much higher value was obtained for the homeo domain $\left(5.4 \times 10^{-8}\right.$ M). From these data we calculate that the $K_{\mathrm{d}}$ of the homeo domain is $5.4 \times 10^{-8} \mathrm{M}$, approximating the protein concentration at $50 \%$ binding. For the POU domain we corrected for the DNA concentration (see Materials and methods) and calculated a $K_{\mathrm{d}}$ of $9 \times 10^{-11} \mathrm{M}$. For proteins having a high binding affinity, Scatchard analysis, varying the recognition site concentration at constant protein concentration, is a more accurate method to determine the $K_{\mathrm{d}}$. Using this technique, we found a $K_{\mathrm{d}}$ of $7 \times 10^{-11} \mathrm{M}$ and $4 \times 10^{-8} \mathrm{M}$ for the POU and homeo domains, respectively. Thus, both methods gave almost identical results.

The POU and homeo domain-binding curves come closer together when the Ad2 oligonucleotide (AATATGATAATGAGGG) is used. This is caused both by a 20fold increase of the homeo domain affinity and a 3 -fold 

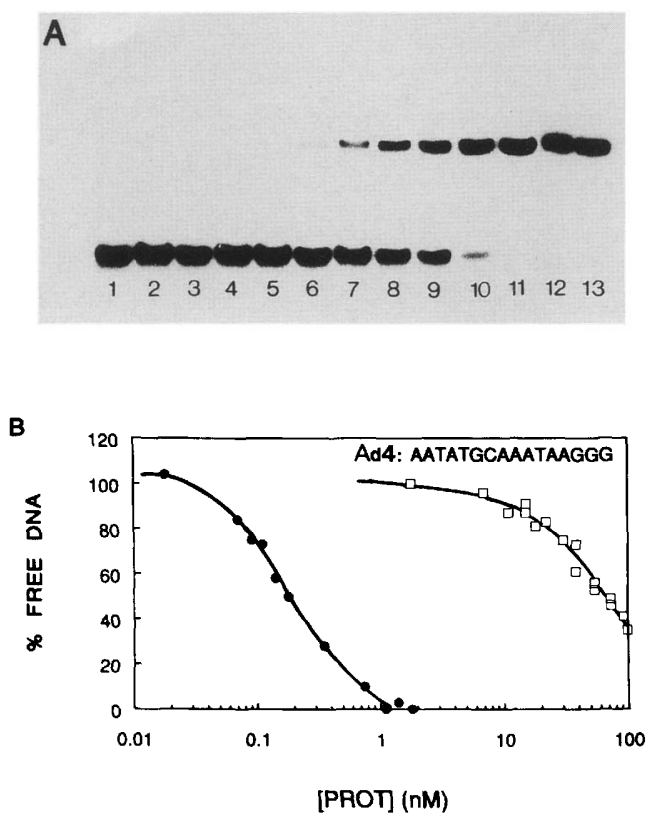

C
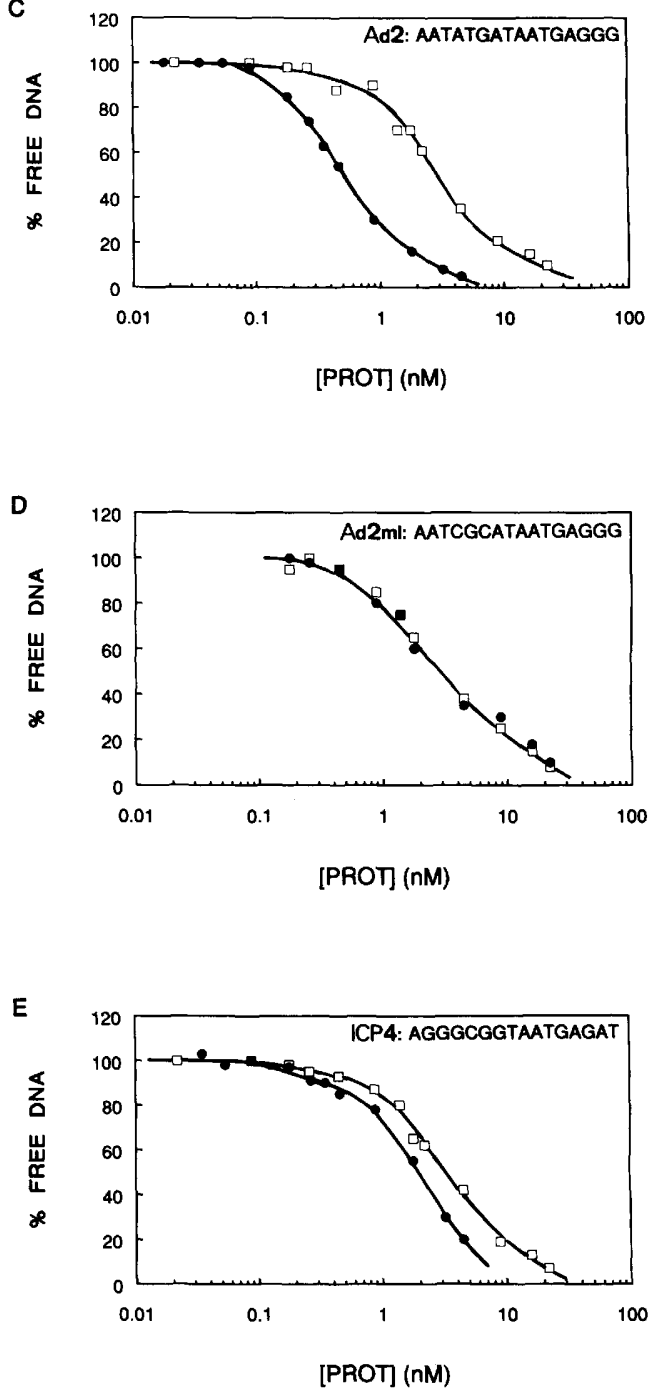

decrease of the affinity for the POU domain (Fig. 7C). When we mutated the left side of the Ad2 octamer (ATG to $C G C$ ), homeo domain binding was unaffected, but the binding affinity for the POU domain decreased to approximately that of the homeo domain (Fig. 7D). This suggests that mutation of the left side of the octamer aborts the contacts made by the POU-specific domain. With the ICP4 TAATGARAT motif (GGGCGGTAATGAGAT), a similar observation was made. The POU domain binds only 1.7-fold more efficiently than the homeo domain (Fig. 7E). Previous experiments suggested that the oct-1 homeo domain has a considerably weaker affinity for the ICP4 TAATGARAT sequence than the POU domain (Sturm and Herr 1988), in contrast to our results. This difference might be explained by the use of poly[d(I-C)]/[d(I-C)]. We observed that the isolated homeo domain is more sensitive to nonspecific competitors like poly $[\mathrm{d}(\mathrm{I}-\mathrm{C})] /[\mathrm{d}(\mathrm{I}-\mathrm{C})]$ than the POU domain. This leads to a reduction of specificity and apparently weak binding of the homeo domain in the presence of competitor.

To contribute to DNA binding, the POU-specific domain must be covalently bound to the homeo domain. Coexpression of the POU-specific domain and the homeo domain does not lead to enhancement of homeo domain binding or to complex formation (not shown; also see Sturm and Herr 1988). The data are summarized in Figure 8.

\section{Discussion}

\section{The octamer as a bipartite recognition sequence}

The results of contact point analysis, as well as the observation that the left part of the POU target sequence can be mutated without affecting homeo domain binding, can be explained by a model in which the Ad2 octamer sequence is divided into two parts: one recognized by the homeo domain, and the other, by the POUspecific region. When ascribing sequence recognition to the POU-specific region, some reservations should be made, because such a function is only inferred from a comparison between the POU and homeo domains. Thus, we cannot exclude a role of the linker sequence. However, this is unlikely, considering the lack of conservation in this part of the protein and the observation that insertions in the linker do not change DNA binding (Sturm and Herr 1988). Using several probes, we and others (Sturm and Herr 1988) were not able to show binding of the POU-specific region directly. This may be caused by an aberrant conformation of the POU-specific

Figure 7. Comparison of the binding affinities of the POU and homeo domains for several octamer motifs. Labeled oligonucleotides were incubated with increasing amounts of POU or homeo domains and assayed by gel retardation. As an example, $A$ shows the result for the homeo domain and the Ad2 oligonucleotide. The results were quantitated by Cerenkov counting of gel slices, and the amount of free DNA was plotted against the concentration of the POU domain $(\Theta)$ or the homeo domain $(\square)$. Probes contained the Ad4 octamer $(B)$, the Ad2 octamer $(C)$, the Ad2ml mutant site $(D)$, or the HSV ICP4 TAATGARAT motif $(E)$. 
Figure 8. Comparison of equilibrium dissociation constants $\left(K_{\mathrm{d}}\right)$ of oct-1 POU and homeo domains for different sites. Sequences were aligned according to the octamer motif. The oct-1 homeo domain recognition sequence, deduced from the $\mathrm{Ad} 2$ contact point analysis is centered. Sequences are from transcription regulatory elements: U2 snRNA enhancer (Mattaj et al. 1985), the $V_{H}$ promoter (Pruijn et al. 1987), the HSV ICP4 TAATGARAT motif (O'Hare and Goding 1988), and the Hox-2.3 promoter region (Verrijzer et al. 1988) or the Ad2 and Ad4 origins; Ad2ml is an Ad2 octamer mutant (O'Hare and Goding 1988). The $K_{d}$ values were calculated from the curves in Fig. 7. All experiments were performed in triplicate, and the deviation was never more than $10 \%$, except for the two Hox -2.3 sites for which the $K_{\mathrm{d}}$ was measured less exactly with a deviation of $25 \%$. In the last column, the ratio $\left(1 / K_{\mathrm{d}}\right)$ of the POU domain to the homeo domain is given as a measure of the relative affinity to the various recognition sites.

region, when present without the remainder of the POU domain, leading to a loss of the DNA-binding capacity. More likely, it is due to a low DNA-binding affinity, as the POU-specific region is only responsible for a limited number of contacts (see below).

At present, we cannot exclude that the structure of the homeo domain or the DNA contacts made by it are influenced by the POU-specific domain. However, the latter is difficult to reconcile with our observation that the contacts in the right part of the octamer do not change upon deletion of the POU-specific domain. Moreover, an octamer site mutated in the left part (Ad2ml) has the same affinity for the complete POU domain as for the homeo domain, making it less likely that the POU-specific domain affects the binding properties of the homeo domain.

An alternative explanation for the role of the POUspecific domain, suggested by García-Blanco et al. (1989), is stabilization of the contacts made by the homeo domain. We consider this less likely in view of the difference in specificity and in DNA contacts between the POU and homeo domains.

\section{The homeo domain recognition sequence within the octamer}

Contact point analysis identified the ATAATGA sequence within the Ad2 octamer as the oct-1 homeo domain target sequence. This motif shows a clear similarity to several homeo box protein sequences, which all contain a TAAT motif (Desplan et al. 1988; Hoey and Levine 1988; Müller et al. 1988; Scott et al. 1989). Furthermore, most backbone contacts made by the oct-1 homeo domain are accessible from one side of the helix. In this respect it resembles other homeo box proteins like yeast Mat $\alpha 2$ (Sauer et al. 1988) and Drosophila Antp (Affolter et al. 1990). Here, we show that the oct-1 POU and homeo domains can bind two murine homeo box protein target sites, Hox-2.3 $\alpha$ and $\beta$ (Figs. 6 and 8). Previously, it was demonstrated that oct- 2 also binds to recognition sequences of several homeo box proteins (Ko et al. 1988; Scheidereit et al. 1988; Thali et al. 1988).

Somewhat unexpectedly, the high-affinity Antp protein-binding site BS2 (CTAATGG; Affolter et al. 1990) does not bind the oct-1 homeo domain. This is probably due to the A-C mutation at position 7 (Fig. 8), which is a homeo domain contact in the Ad2 octamer. From the limited amount of quantitative data, we deduce RTAATGA ( $R=$ purine) as the optimal oct-1 homeo domain target site.

\section{Oct-1 binding to the HSV ICP4 TAATGARAT sequence is mainly directed by the homeo domain}

VP16 or VMw65 is an HSV protein that trans-activates the HSV immediate early (IE) genes, mediated by the TAATGARAT motif in promoters of various IE genes. For trans-activation, VP16 must complex to the oct-1 protein (Gerster and Roeder 1988; O'Hare and Goding 1988; O'Hare et al. 1988), which is directed by the homeo domain (Stern et al. 1989). The VP16 TAATGARAT target sequence overlaps in some promoters, like ICPO (IE110), with the octamer sequence. In others, like ICP4 (IE175), no such overlap exists. Nevertheless, weak binding of oct-1 can be observed, suggesting that the TAATGARAT motif is a degenerate octamer (Baumruker et al. 1988; O'Hare and Goding 1988; Aprhys et al. 1989|. From DEPC interference studies, Baumruker et al. (1988) concluded that oct-1 contacts the entire TAATGARAT motif. Using purified proteins, we observed that mutations in the "RAT" part of the TAATGARAT sequence hardly affect the binding affinity of the complete POU domain (Fig. 8, cf. Ad2ml, ICP4, Hox-2.3 $\alpha$, and Hox-2.3 $\beta$ ). Also, deletion of the POU-specific domain has only a very limited effect on binding to the TAATGARAT motif. Therefore, the additional contacts identified by Baumruker et al. (1988) may not be an important determinant for the binding affinity.

\section{Contribution of the POU-specific domain to DNA binding}

It has been proposed that in a protein-DNA complex, a large part of the binding energy is derived from electrostatic interactions with the DNA backbone (von Hippel and Berg 1986). Because they are generally independent of base sequence, these interactions do not contribute to 
specificity of site recognition. Base contacts determine the sequence specificity of a DNA-binding protein while they provide only a small part of the binding energy. Our results are consistent with such a model. The POU-specific domain makes half of the base contacts identified in the Ad2 octamer, while the majority of the backbone contacts are made by the homeo domain. This probably explains why the contribution of the POU-specific domain to the binding energy is relatively weak and no independent binding is observed. Also the high affinity of the homeo domain for nonspecific DNA $\left(K_{\mathrm{d}}= \pm 10^{-6}\right.$ M) is in agreement with this model. Thus, even in the absence of a homeo domain recognition sequence, the contribution of the homeo domain to DNA binding of the complete POU domain is considerable.

Although an intact homeo domain is required for DNA binding for all POU proteins studied so far, the contribution to DNA binding of the various POU-specific domains seems to differ. The POU-specific domain does not contain a recognizable DNA-binding motif. Therefore, it is difficult to ascribe the additional contacts to a particular region of this domain. Triple alanine substitutions and deletion studies indicated that the complete oct-1 POU-specific domain is involved in DNA binding (Sturm and Herr 1988). Deletion of 11 amino acids at the amino-terminal part of the oct-2 POU-specific domain impairs transcription but only weakly affects binding to the canonical octamer. Upon deletion of the first 15 amino acids of the POU-specific domain, DNA binding could not be detected anymore (Müller-Immerglück et al. 1990). For GHF-1 (Pit-1), deletion of the amino-terminal half of the POU-specific domain results in 2.5- to 3-fold lower binding activity, whereas the DNase I footprints remained similar (Theill et al. 1989). In the case of oct-4, DNA binding still occurs when the POU-specific domain is almost completely deleted (Schöler et al. 1990).

By comparison of these data it is not yet clear which part of the POU-specific domain is involved in DNA binding. Moreover, we show that the contribution of the oct-1 POU-specific domain to DNA binding depends on the target sequence. If this also applies to the other POU proteins it could complicate comparisons. In addition to DNA binding, the conservation of the POU-specific domain might reflect other functional constraints. The oct-2 POU-specific domain is involved in transcriptional activation (Müller-Immerglück et al. 1990), and the oct-1 POU-specific domain is absolutely required for stimulation of DNA replication (Verrijzer et al. 1990).

What makes an optimal oct-1 POU recognition sequence? The octamer motif present in the Ad4 origin and the $\mathrm{V}_{\mathrm{H}}$ promoter is the strongest oct-1-binding site identified so far (Pruijn et al. 1987 and this paper). Mutations at positions 7 and 8 from AT to CA, changing the Ad2 octamer to the Ad4 octamer, lead to a higher affinity for the POU domain (Fig. 8). Paradoxically, binding of the homeo domain is strongly decreased. This shows that an optimal POU-binding site is not created by simply joining a strong POU-specific and homeo domain target sequence. Possibly, flexibility of the DNA, in addition to direct contacts, also determines the affinity of a particular site. Such a mechanism has been reported for cap (Gartenberg and Crothers 1988) and the bacteriophage 434 repressor (Koudelka et al. 1988). In this respect, it is noteworthy that we recently obtained evidence for bending of DNA by the POU domain (C.P. Verrijzer et al., in prep|.

\section{Materials and methods}

\section{Recombinant vaccinia viruses}

The production of recombinant vaccinia viruses, expressing the oct-1 POU and homeo domains, has been described (Verrijzer et al. 1990). To prepare vaccinia virus containing the cDNA sequence encoding the POU-specific domain, the 370-bp EcoRI fragment from mutant 1-23/269-743 (Verrijzer et al. 1990) was cloned in pATA-18-STOP. This leads to a construct encoding amino acids $1-23$ and 269-368 to which SSSVPGIL was added carboxy-terminally. The POU-encoding recombinant virus expressed amino acids $1-23$ and $269-440$ to which TIAE was added carboxy-terminally. For the homeo domain, amino acids 369-440 were expressed and a methionine residue was added at the amino terminus.

\section{Preparation of extracts}

Nuclear extracts were prepared from $3 \times 10^{9} \mathrm{HeLa}$ cells $24 \mathrm{hr}$ postinfection. The cells were collected by centrifugation at low speed (10 $\mathrm{min}, 2500 \mathrm{rpm}$ ), washed twice with PBS containing $0.5 \mathrm{mM} \mathrm{MgCl}_{2}$, and resuspended in $30 \mathrm{ml}$ hypotonic buffer $(20$ mM HEPES-KOH at $\mathrm{pH} 7.51,5 \mathrm{~mm} \mathrm{KCl}, 0.5 \mathrm{~mm} \mathrm{MgCl}_{2}, 2 \mathrm{~mm}$ PMSF, and $0.1 \%$ Nonidet P-40). After $20 \mathrm{~min}$, the cells were Dounce-homogenized. The nuclei were collected by low-speed centrifugation and resuspended in $10 \mathrm{ml}$ of the same buffer containing $0.3 \mathrm{M} \mathrm{NaCl}$. After $60 \mathrm{~min}$, the suspension was centrifuged for $10 \mathrm{~min}$ at $3500 \mathrm{rpm}$. The supernatant was centrifuged at $100,000 \mathrm{~g}$ for $30 \mathrm{~min}$. Glycerol was added to a final concentration of $20 \%$, and aliquots were stored at $-20^{\circ} \mathrm{C}$. All procedures were on ice and centrifugation was at $4^{\circ} \mathrm{C}$. Cytoplasmic extracts were made as described (Verrijzer et al. 1990).

\section{Protein purification}

Two buffers were used for further purification: buffer A $25 \mathrm{~mm}$ Tris- $\mathrm{HCl}$ at $\mathrm{pH} 8.0,1 \mathrm{mM}$ PMSF, $0.02 \%$ Nonidet P-40, and $20 \%$ glycerol) and buffer $\mathrm{B}$, which is almost identical to buffer A, except HEPES $(\mathrm{pH} 8.0)$ is used instead of Tris. For the purification of the homeo domain, nuclear extracts were diluted with buffer $A$ to $100 \mathrm{mM} \mathrm{NaCl}$ and applied to a $40-\mathrm{ml}$ DEAE column. The flowthrough was fractionated on an $18-\mathrm{ml}$ fast-flow $\mathrm{S}$ column in buffer and eluted with a $120-\mathrm{ml}$ linear gradient of $\mathrm{B} / 100-400 \mathrm{~mm} \mathrm{NaCl}$ and assayed by gel retardation. The homeo domain eluted $\sim 300 \mathrm{~mm} \mathrm{NaCl}$. Peak fractions were combined, diluted to $30 \mathrm{mM} \mathrm{NaCl}$ with buffer $\mathrm{A}$, and loaded onto a $20-\mathrm{ml}$ fast-flow $\mathrm{Q}$ column. The flowthrough was further fractionated on a 9-ml heparin-Sepharose column. The homeo domain was eluted by a linear gradient $(\mathrm{B} / 100-600 \mathrm{~mm} \mathrm{NaCl})$ and peaked at $500 \mathrm{~mm} \mathrm{NaCl}$. Homeo domain fractions were combined, diluted to $100 \mathrm{~mm}$, and applied to a $5-\mathrm{ml}$ singlestranded DNA-cellulose column. Homeo domain was eluted by a step elution with $\mathrm{B} / 400 \mathrm{mM} \mathrm{NaCl}$. A similar protocol was used for the purification of the POU domain. The POU domain eluted at $220 \mathrm{~mm}$ and $300 \mathrm{~mm}$ from the fast-flow $\mathrm{S}$ and heparin-Sepharose columns, respectively. All procedures were 
on ice or at $4^{\circ} \mathrm{C}$. Protein concentrations were determined by using the Bio-Rad dye reagent with BSA as a standard. The yields were $\sim 0.5 \mathrm{mg}$ of the POU domain and $0.4 \mathrm{mg}$ for the homeo domain.

\section{Gel retardation}

Oligodeoxynucleotides used for gel retardation were end-labeled with T4 polynucleotide kinase and purified by preparative polyacrylamide gel electrophoresis by using standard procedures (Maniatis et al. 1982). The sequences of the doublestranded oligonucleotides are Ad4, CGAATATGCAAATAAGGC; Ad2, AGGCCAATATGATAATGAGGGGGT; Ad2ml, AGGCCAATCGCATAATGAGGGGGT; TAAT8 (ICP4), AGGGCGGTAATGAGATGCCATGT; BS2-18 (Antp), CTCTAATGGCTTTTTCTC. The DNA concentration of the oligonucleotides used for quantitative analysis was determined both by absorption at $260 \mathrm{~nm}$ and by comparison with marker DNA in ethidium bromide-stained polyacrylamide gels. Binding studies with the Hox-2.3 promoter region were performed with a 150-bp SalI-EcoRV fragment $(686-836 \mathrm{bp}$; Verrijzer et al. 1988) containing two Hox-1.3-binding sites: $\alpha$ (799-806) and $\beta$ (741-747; Odenwald et al. 1989).

Binding reactions were carried out in $20 \mu$ l binding buffer $(20$ mM HEPES-KOH at pH 7.5, $1 \mathrm{~mm}$ EDTA, $1 \mathrm{~mm}$ DTT, $0.025 \%$ Nonidet P-40, 4\% Ficoll, and $125 \mu \mathrm{g} / \mathrm{ml}$ BSA). After $60 \mathrm{~min}$ on ice, bound and free DNAs were resolved on a $15 \%$ polyacrylamide gel run in $0.5 \times \mathrm{TBE}$ at $4^{\circ} \mathrm{C}$ and quantified by Cerenkov counting of gel slices. The equilibrium dissociation constant $\left(K_{d}\right)$ in a bimolecular reaction is given by the equation $1 / K_{\mathrm{d}}=D_{\mathrm{b}} / D_{\mathrm{f}}\left(P_{\mathrm{t}}-D_{\mathrm{b}}\right)$. The concentrations of free DNA $\left(D_{\mathrm{f}}\right)$ and bound DNA $\left(D_{\mathrm{b}}\right)$ were calculated from the gel quantification. The concentration of input DNA was $2 \times 10^{-10} \mathrm{M}$. The total protein concentration $\left(P_{t}\right)$ was calculated by using a deduced molecular mass of 26.7 and $10.6 \mathrm{kD}$ for the POU and homeo domains, respectively. At half-saturation, the equation becomes $K_{\mathrm{d}}=P_{\mathrm{b}}-D_{\mathrm{t}}$ in which $D_{\mathrm{b}}=10^{-10} \mathrm{M}$. For Scatchard analysis, the equation was rearranged into $D_{\mathrm{b}} / D_{\mathrm{f}}=\left(P_{\mathrm{t}}-D_{\mathrm{b}}\right) / K_{\mathrm{d}}$. The $K_{\mathrm{d}}$ value was obtained from the slope of the plot of $D_{\mathrm{b}} / D_{\mathrm{f}}$ versus $D_{\mathrm{b}}$.

\section{DNase I and hydroxyl radical footprinting}

Binding reactions were performed on ice in $50 \mu$ l binding buffer in the presence of $100 \mathrm{ng}$ poly[d(I-C) $] /[\mathrm{d}(\mathrm{I}-\mathrm{C})]$. Approximately 40 $\mathrm{ng}$ POU and $60 \mathrm{ng}$ homeo domain were added to initiate the binding reaction. After $1 \mathrm{hr}, 5 \mu \mathrm{l} 50 \mathrm{mM} \mathrm{MgCl}_{2}$ and 0.02 units DNase I were added. Digestion was allowed for $90 \mathrm{sec}$ at $25^{\circ} \mathrm{C}$ and terminated by addition of $3 \mu \mathrm{l} 0.2 \mathrm{M}$ EDTA, $10 \%$ SDS. For hydroxyl radical footprinting (Tullius and Dombroski 1986), 9 $\mu \mathrm{l}$ of a fresh mixture of $0.13 \mathrm{~mm}$ EDTA, $0.07 \mathrm{~mm}$ ferrous ammonium sulfate, $2 \% \mathrm{H}_{2} \mathrm{O}_{2}$, and $6.7 \mathrm{mM}$ sodium ascorbate was added. After $3 \mathrm{~min}$, the cleavage reaction was stopped by addition of $30 \mu \mathrm{l} 0.2 \mathrm{M}$ thiourea. One microgram of calf thymus DNA was added, followed by phenol-chloroform extraction and ethanol precipitation, and the samples were analyzed on an $8 \%$ denaturing polyacrylamide gel. The DNA used in the footprint assays was a 110 -bp EcoRI-XbaI fragment from pHRI, containing the Ad2 origin (Hay 1985). The bottom strand was labeled at the $5^{\prime}$ end of the $\mathrm{XbaI}$ site by $\mathrm{T} 4$ polynucleotide kinase. The top strand was labeled with $\left[\alpha^{-32} \mathrm{P}\right] \mathrm{dCTP}$ at the $X b a \mathrm{I}$ site by DNA polymerase I (Klenow fragment). Approximately 2 ng probe $(30,000 \mathrm{cpm})$ was used for each reaction. Sequencing reactions were performed as described (Maxam and Gilbert 1980).

\section{Interference experiments}

For methylation interference experiments, labeled DNA fragments were methylated with DMS by the method of Siebenlist and Gilbert (1980). The DEPC modification was performed according to Sturm et al. (1987). Probes were purified on a $6 \%$ polyacrylamide gel. The band shift assay was as described above; only $80,000 \mathrm{cpm}$ modified probe DNA was used per assay and $20 \mathrm{ng}$ of the POU domain or $50 \mathrm{ng}$ of the homeo domain. DNA was eluted from the gel (Maxam and Gilbert 1980), phenol-extracted, and ethanol-precipitated twice with $1 \mu \mathrm{g}$ carrier calf thymus DNA. Pellets were dissolved in $100 \mu \mathrm{l} \mathrm{H}_{2} \mathrm{O}$, and $10 \mu \mathrm{l} 100 \mathrm{mM} \mathrm{KPO}{ }_{4}(\mathrm{pH} 7.0)$ was added. Samples were heated for $15 \mathrm{~min}$ at $90^{\circ} \mathrm{C}$, cooled on ice, and $10 \mu \mathrm{l} 1 \mathrm{M} \mathrm{NaOH}$ was added, followed by incubation at $90^{\circ} \mathrm{C}$ for $30 \mathrm{~min}$. After cooling on ice, $13 \mu \mathrm{l} 1 \mathrm{M} \mathrm{HAc}$ and $8 \mu \mathrm{l} 3 \mathrm{M} \mathrm{NaAc}$ were added. Samples were phenol-chloroform-extracted once and ethanolprecipitated twice. Pellets were dissolved in $2 \mu \mathrm{l}$ sample buffer (80\% formamide, $20 \mathrm{mM} \mathrm{NaOH}$ ), and products were analyzed on an $8 \%$ denaturing polyacrylamide gel. The results of footprint and interference experiments were quantified by densitometric scanning of the autoradiographs with a laser densitometer (Ultroscan XL, Pharmacia LKB). Calculated levels of interference were normalized for regions outside the protected area.

\section{Acknowledgments}

We are grateful to Winship Herr for providing pBS oct- $1^{+}$and pBS oct- ${ }^{+} \triangle \mathrm{BH}$ DNA. We thank Drs. Affolter and Gehring for the Antp BS2-18 DNA and for making data available before publication, Peter O'Hare for TAAT8, Ad2, and Ad2ml, and Frits Meylink for Hox-2.3 promoter DNA. Thanks are also due to Wim van Driel for useful discussions and to Erik de Vries and Yvonne Mul for critical reading of the manuscript. This work was supported, in part, by the Netherlands Foundation for Chemical Research (SON), with financial support from the Netherlands Organization for Scientific Research (NWO).

The publication costs of this article were defrayed in part by payment of page charges. This article must therefore be hereby marked "advertisement" in accordance with 18 USC section 1734 solely to indicate this fact.

\section{References}

Affolter, M., A. Percival-Smith, M. Müller, W. Leupin, and W. Gehring. 1990. DNA binding properties of the purified Antennapedia homeodomain. Proc. Natl. Acad. Sci. 87: 40934097.

Aprhys, C.M.J., D.M. Ciufo, E.A. O'Neill, T.J. Kelly, and G.S. Hayward. 1989. Overlapping octamer and TAATGARAT motifs in the VF65-response elements in Herpes Simplex Virus Immediate-Early promoters represent independent binding sites for cellular Nuclear Factor III. J. Virol. 63: $2798-2812$.

Baumruker, T., R. Sturm, and W. Herr. 1988. OBP100 binds remarkably degenerate octamer motifs through specific interactions with flanking sequences. Genes Dev. 2: 1400-1413.

Bodner, M., J.-L. Castrillo, L.T. Theill, T. Deerinck, M. Ellisman, and M. Karin. 1988. The pituitary-specific transcription factor GHF-1 is a homeobox-containing protein. Cell 55: 505-518.

Bürglin, T.R., M. Finney, A. Coulson, and G. Ruvkun. 1989. Caenorhabditis elegans has scores of homeobox-containing genes. Nature 341: 239-243.

Clerc, R.G., L.M. Corcoran, J.H. LeBowitz, D. Baltimore, and P.A. Sharp. 1988. The B-cell-specific Oct-2 protein contains 
POU box and homeo box-type domains. Genes Dev. 2: $1570-1581$.

Desplan, C., J. Theis, and P.H. O'Farrell. 1988. The sequence specificity of homeodomain-DNA interaction. Cell 54: 1081-1090.

Finney, M., G. Ruvkun, and H.R. Horvitz. 1988. The C. elegans cell lineage and differentiation gene unc- 86 encodes a protein containing a homeodomain and extended sequence similarity to mammalian transcription factors. Cell 55: 757769.

Fletcher, C., N. Heintz, and R.G. Roeder. 1987. Purification and characterization of OTF-1, a transcription factor regulating cell cycle expression of a human histone $\mathrm{H} 2 \mathrm{~B}$ gene. Cell 51: 773-781.

García-Blanco, M.A., R.G. Clerc, and P.A. Sharp. 1989. The DNA-binding homeo domain of the Oct-2 protein. Genes Dev. 3: 739-745.

Gartenberg, M.R. and D.M. Crothers. 1988. DNA sequence determinants of CAP-induced bending and protein binding affinity. Nature 333: 824-829.

Gerster, T. and R.G. Roeder. 1988. A herpesvirus trans-activating protein interacts with transcription factor OTF-I and other cellular proteins. Proc. Natl. Acad. Sci. 85: 63476351.

Goding, C.R. and P. O'Hare. 1989. Herpes Simplex Virus Vmw65-Octamer binding protein interaction: A paradigm for combinatorial control of transcription. Virology 173: $363-367$.

Hall, M.N. and A.D. Johnson. 1987. Homeo domain of the yeast repressor $\alpha 2$ is a sequence-specific DNA-binding domain but is not sufficient for repression. Science 237: 1007-1012.

Hay, R.T. 1985. Origin of Adenovirus DNA replication: Role of the Nuclear Factor I binding site in vivo. I. Mol. Biol. 186: $129-136$

He, X., M.N. Treacy, D.M. Simmons, H.A. Ingraham, L.W. Swanson, and M.G. Rosenfeld. 1989. Expression of a large family of POU-domain regulatory genes in mammalian brain development. Nature 340: 35-42.

Herr, W., R.A. Sturm, R.G. Clerc, L.M. Corcoran, D. Baltimore, P.A. Sharp, H.A. Ingraham, M.G. Rosenfeld, M. Finney, G. Ruvkun, and H.R. Horvitz. 1988. The POU domain: A large conserved region in the mammalian pit-1, oct-1, oct-2, and Caenorhabditis elegans unc-86 gene products. Genes Dev. 2: 1513-1516.

Hoey, T. and M. Levine. 1988. Divergent homeobox proteins recognize similar DNA sequences in Drosophila. Nature 332: $858-861$.

Ingraham, H.A., R. Cheng, H.J. Mangalam, H.P. Elsholtz, S.E. Flyn, C.R. Lin, D.M. Simmons, L. Swanson, and M.G. Rosenfeld. 1988. A tissue-specific transcription factor containing a homeodomain specifies a pituitary phenotype. Cell 55: 519-529.

Johnson, W.A. and J. Hirsh. 1990. Binding of a Drosophila POU-domain protein to a sequence element regulating gene expression in specific dopaminergic neurons. Nature 343: 467-470.

Ko, H.S., P. Fast, W. McBride, and L.M. Staudt. 1988. A human protein specific for immunoglobulin octamer DNA motif contains a functional homeobox domain. Cell 55: 135-144.

Koudelka, G.B., P. Harbury, S.C. Harrison, and M. Ptashne. 1988. DNA twisting and the affinity of bacteriophage 434 operator for bacteriophage 434 repressor. Proc. Natl. Acad. Sci. 85: 4633-4637.

Lenardo, M.J., L. Staudt, P. Robbins, A. Kuang, R.C. Mulligan, and D. Baltimore. 1989. Repression of the IgH enhancer in teratocarcinoma cells associated with a novel octamer factor. Science 243: 544-546.

Maniatis, T., E.F. Fritsch, and J. Sambrook. 1982. Molecular cloning: A laboratory manual. Cold Spring Harbor Laboratory, Cold Spring Harbor, New York.

Mattaj, I.W., S. Lienhard, J. Jiricny, and E.M. De Robertis. 1985. An enhancer like sequence within the Xenopus U2 gene promoter facilitates the formation of stable transcription complexes. Nature 316: 163-167.

Maxam, A.M. and W. Gilbert. 1980. Sequencing end-labeled DNA with base-specific chemical cleavages. Methods Enzymol. 65: 499-560.

Mihara, H. and E.T. Kaiser. 1988. A chemically synthesized Antennapedia homeo domain binds to a specific DNA sequence. Science 242: 925-927.

Müller, M., M. Affolter, W. Leupen, G. Otting, K. Wüthrich, and W.J. Gehring. 1988. Isolation and sequence-specific DNA binding of the Antennapedia homeodomain. EMBO J. 7: 4299-4304.

Müller-Immerglück, M.M., R. Siegfried, W. Schaffner, and P. Matthias. 1988. A cloned octamer transcription factor stimulates transcription from lymphoid-specific promoters in non-B cells. Nature 336: 544-551.

Müller-Immerglück, M.M., W. Schaffner, and P. Matthias. 1990. Transcription factor Oct-2A contains functionally redundant activating domains and works selectively from a promoter but not from a remote enhancer position in nonlymphoid (HeLa) cells. EMBO I. 9: 1625-1634.

Odenwald, W.F., J. Garbern, H. Arnheiter, E. Tournier-Lasserve, and R.A. Lazzarini. 1989. The Hox-1.3 homeo box protein is a sequence-specific DNA-binding phosphoprotein. Genes Dev. 3: $158-172$.

O'Hare, P. and C.R. Goding. 1988. Herpes Simplex Virus regulatory elements and the immunoglobulin octamer domain bind a common factor and are both targets for virion transactivation. Cell 52: 435-445.

O'Hare, P., C.R. Goding, and A. Haigh. 1988. Direct combinatorial interaction between a herpes simplex virus regulatory protein and a cellular octamer-binding factor mediates specific induction of virus immediate-early gene expression. EMBO I. 7: 4231-4238.

Okamoto, K., H. Okazawa, A. Okuda, M. Sakai, M. Muramatsu, and H. Hamada. 1990. A novel octamer transcription factor is differentially expressed in mouse embryonic cells. Cell 60: $461-472$.

O'Neill, E.A. and T.J. Kelly. 1988. Purification and characterization of Nuclear Factor III (Origin Recognition Protein C), a sequence-specific DNA binding protein required for efficient initiation of adenovirus DNA replication. I. Biol. Chem. 263: 931-937.

Petryniak, B., L.M. Staudt, C.E. Postema, W.T. McCormack, and C.B. Thomson. 1990. Characterization of chicken octamer-binding proteins demonstrates that the POU domain containing homeobox transcription factors have been highly conserved during vertebrate evolution. Proc. Natl. Acad. Sci. 87: 1099-1103.

Pruijn, G.J.M., W. van Driel, and P.C. van der Vliet. 1986. Nuclear Factor III, a novel sequence-specific DNA binding protein from HeLa cells stimulating adenovirus DNA replication. Nature 322: 656-659.

Pruijn, G.J.M., W. van Driel, R.T. van Miltenburg, and P.C. van der Vliet. 1987. Promoter and enhancer elements containing a conserved sequence motif are recognized by Nuclear Factor III, a protein stimulating adenovirus DNA replication. EMBO J. 6: $3771-3778$.

Pruijn, G.J.M., R.T. van Miltenburg, J.A.J. Claessens, and P.C. van der Vliet. 1988. Interaction between the octamer- 
binding protein Nuclear Factor III and the adenovirus origin of DNA replication. I. Virol. 62: 3092-3102.

Sauer, R.T., D.L. Smith, and A.D. Johnson. 1988. Flexibility of the yeast $\alpha 2$ repressor enables it to occupy the ends of its operator, leaving the center free. Genes Dev. 2: 807-816.

Scheidereit, C., J.A. Cromlish, T. Gerster, K. Kawakami, C. Balmaceda, R.A. Currie, and R.G. Roeder. 1988. A human lymphoid-specific transcription factor that activates immunoglobulin genes is a homoeobox protein. Nature 336: 551557.

Schöler, H.R., A.K. Hatzopoulos, R. Balling, N. Suzuki, and P. Gruss. 1989a. A family of octamer-specific proteins present during mouse embryogenesis: Evidence for germline-specific expression of an Oct factor. EMBO $J$. 8: 2543-2550.

Schöler, H.R., R. Balling, A.K. Hatzopoulos, N. Suzuki, and P. Gruss. 1989b. Octamer binding proteins confer transcriptional activity in early mouse embryogenesis. EMBO $I$. 8: $2551-2557$.

Schöler, H.R., S. Ruppert, R. Balling, N. Suzuki, K. Chowdhury, and P. Gruss. 1990. New type of POU domain in germ linespecific protein Oct-4. Nature 344: 435-438.

Scott, M.P., J.W. Tamkun, and G.W. Hartzell III. 1989. The structure and function of the homeodomain. Biochim. Biophys. Acta 989: 25-48.

Siebenlist, U. and W. Gilbert. 1980. Contacts between E. coli RNA polymerase and an early promoter of phage T7. Proc. Natl. Acad. Sci. 77: 122-126.

Singh, H., R. Sen, D. Baltimore, and P.A. Sharp. 1986. A nuclear factor that binds to a conserved sequence motif in transcriptional control elements of immunoglobulin genes. Nature 319: $154-158$.

Smith, D.P. and R.W. Old. 1990. Nucleotide sequence of Xenopus laevis Oct-1 cDNA. Nucleic Acids Res. 18: 369.

Stern, S., M. Tanaka, and W. Herr. 1989. The Oct-1 homoeodomain directs formation of a multiprotein-DNA complex with the HSV transactivator VP16. Nature 341: 624-630.

Sturm, R., T. Baumruker, B.R. Franza, Ir., and W. Herr. 1987. A $100-\mathrm{kD}$ HeLa cell octamer binding protein (OBP100) interacts differently with two separate octamer-related sequences within the SV40 enhancer. Genes Dev. 1: 11471160.

Sturm, R.A., G. Das, and W. Herr. 1988. The ubiquitous octamer-binding protein Oct-1 contains a POU domain with a homeo box subdomain. Genes Dev. 2: 1582-1599.

Sturm, R.A. and W. Herr. 1988. The POU domain is a bipartite DNA-binding structure. Nature 336: 601-604.

Thali, M., M.M. Müller, M. DeLorenzi, P. Mathias, and M. Bienz. 1988. Drosophila homeotic genes encode transcriptional activators similar to mammalian OTF-2. Nature 336: $598-601$.

Theill, L.E., J. Castrillo, D. Wu, and M. Karin. 1989. Dissection of functional domains of the pituitary-specific transcription factor GHF-1. Nature 342: 945-948.

Tullius, T.D. and B.A. Dombroski. 1986. Hydroxyl radical footprinting: High-resolution information about DNA-protein contacts and application to Lambda repressor and Cro protein. Proc. Natl. Acad. Sci. 83: 5469-5473.

Verrijzer, C.P., W. de Graaf, J. Deschamp, and J. Meijlink. 1988. Nucleotide sequence of the Hox 2.3 gene region. Nucleic Acids Res. 16: 2729.

Verrijzer, C.P., A.J. Kal, and P.C. van der Vliet. 1990. The DNA binding domain (POU domain) of transcription factor oct-1 suffices for stimulation of DNA replication. EMBO $I$. 9: $1883-1888$.

von Hippel, P.H. and O.G. Berg. 1986. On the specificity of DNA-protein interactions. Proc. Natl. Acad. Sci. 83: 1608-
1612.

Wides, R.J., M.D. Challberg, D.R. Rawlins, and T.J. Kelly. 1987. Adenovirus origin of DNA replication: Sequence requirements for replication in vitro. Mol. Cell. Biol. 7: 864-874. 


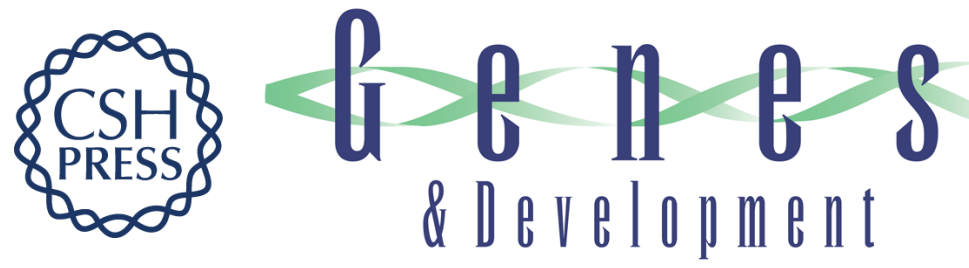

\section{The oct-1 homeo domain contacts only part of the octamer sequence and full oct-1 DNA-binding activity requires the POU-specific domain.}

C P Verrijzer, A J Kal and P C van der Vliet

Genes Dev. 1990, 4:

Access the most recent version at doi:10.1101/gad.4.11.1964

References This article cites 58 articles, 22 of which can be accessed free at:

http://genesdev.cshlp.org/content/4/11/1964.full.html\#ref-list-1

License

Email Alerting

Service right corner of the article or click here.

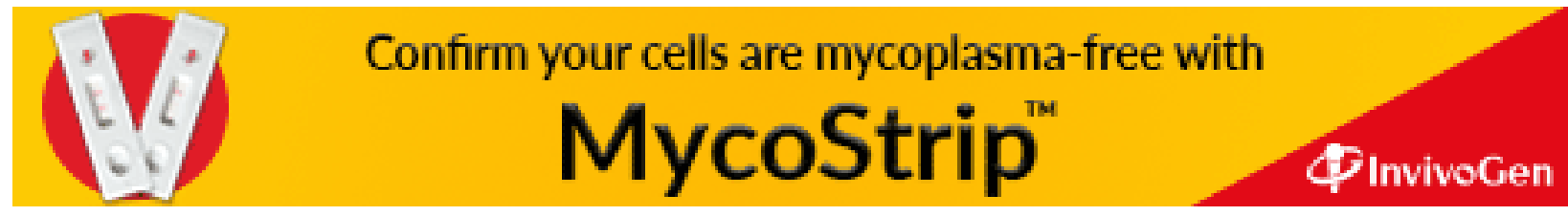

